\title{
EFEITO DA DENSIDADE DE PLANTAS NAS CARACTERÍSTICAS AGRONÔMICAS DE DOIS GENÓTIPOS DE SOJA NO NOROESTE PAULISTA
}

\author{
SANTOS, Guilherme Xavier Lúcio ${ }^{1}$; FINOTO, Everton Luis ${ }^{2}$; CORDEIRO JUNIOR, Paulo Sérgio³; \\ TOKUDA, Flávio Sueo ${ }^{4}$; MARTINS, Mônica Helena ${ }^{1}$
}

ISSUE DOI: $10.3738 / 1982.2278 .3010$

\begin{abstract}
RESUMO: A densidade de plantas de soja assume papel importante no contexto da produção de grãos no Estado de São Paulo, necessitando de estudos técnico-científicos em regiões produtoras, para melhor compreensão das características fenotípicas das cultivares disponíveis aos produtores. Assim, o presente trabalho teve por objetivo avaliar o comportamento agronômico de dois cultivares modernos de soja na região Noroeste do Estado de São Paulo. O experimento foi instalado no município de Riolândia, SP. O delineamento experimental utilizado foi em blocos ao acaso com parcelas sub-dividas e 4 repetições. $O$ tratamento principal consistiu na utilização de duas cultivares comerciais: BRS 1074 IPRO e BRS 1001 IPRO, as sub-parcelas consistiram em três densidades de semeadura: 8, 12 e 18 sementes por metro nas linhas de semeadura espaçadas a $45 \mathrm{~cm}$. Por ocasião da colheita avaliaram-se os seguintes caracteres: altura de planta, altura de inserção da primeira vagem, índice de acamamento, peso de mil sementes e produtividade de grãos. Os dados obtidos foram submetidos a análise de variância pelo teste F, e as médias comparadas pelo teste de Tukey 5\%. Na menor densidade, as plantas são mais baixas, acamam menos, e apresentam maior porcentagem de sobrevivência. Não houve diferença entre os dois cultivares de soja quanto à produtividade de grãos, que diminuiu com o aumento da densidade de plantas nas linhas.
\end{abstract}

Palavras-chave: Glycine max. Densidade de semeadura. População de plantas. Componentes da produção.

SUMMARY: Soybean plants density plays an important role in the context of grain production in São Paulo State, Brazil, requiring technical and scientific studies in producing regions, in order to better understand the phenotypic characteristics of the cultivars available to producers. Thus, the present work had the objective of evaluating the agronomic behavior of two modern soybean cultivars in the northwest region of São Paulo State. The experiment was installed in Riolândia, SP. The experimental design was in randomized blocks with split plot and 4 replicates. The main treatment consisted of two commercial cultivars: BRS 1074 IPRO and BRS 1001 IPRO, the subplots consisted of three sowing densities: 8,12 and 18 seeds per meter at the sowing line. At the time of harvest, the following characteristics were evaluated: plant height at maturity, height of insertion of the first pod, lodging index, weight of one thousand seeds and grain productivity. The data were submitted to analysis of variance by the $\mathrm{F}$ test, and the means were compared by the Tukey 5\% test. At lower densities, the plants are lower, less dormant, and have a higher percentage of survival. Soybean productivity increases with the reduction of plant density in the lines.

Keywords: Glycine max. Sowing density. Plants population. Production components.

\section{INTRODUÇÃO}

A cultura da soja (Glycine max (L.) Merrill) ocupa papel importante na economia mundial, sendo cultivada em quase todas as partes do mundo. O Brasil é o segundo maior produtor mundial e o maior da América Latina. No ano agrícola 2016/17, foram cultivados 33,9 milhões de ha ${ }^{-1}$, sendo produzidos 114,1 milhões de toneladas de soja, representando uma produtividade média de 3,36 ton $\mathrm{ha}^{-1}$. Para o ano agrícola 2017/18 a estimativa é de uma área cultivada de 35 milhões de ha ${ }^{-1}$, com a produção de 111,5

\footnotetext{
${ }^{1}$ Engenheiro Agrônomo, bolsista de aperfeiçoamento técnico - FUNDAG, APTA - PRDTA Centro Norte, Pindorama, SP:

${ }^{2}$ Pesquisador Científico, Dr. - APTA - PRDTA Centro Norte, Pindorama, SP;

${ }^{3}$ Engenheiro Agrônomo, mestrando em Produção Vegetal - UNESP/FCAV - Departamento de Engenharia Rural, Jaboticabal, SP;

${ }^{4}$ Assistente Agropecuário - CATI - CA Riolândia, Riolândia, SP.
} 
milhões de toneladas de soja (CONAB, 2018). Dentro das culturas de grãos, a da soja destaca-se no cenário nacional, sendo a primeira colocada em área plantada.

O excelente desempenho da cultura da soja na região Noroeste do Estado de São Paulo, deve-se à adoção, pelos produtores, de novas tecnologias, principalmente das relacionadas com o fator cultivar resistente às doenças, estresse hídrico e com maior potencial produtivo.

A maior expressão do potencial produtivo das cultivares, entretanto, depende das condições do meio onde as plantas irão desenvolver-se. Assim, alterações relacionadas com a população de plantas podem aumentar os ganhos em produtividade, pois essa característica é consequência da densidade das plantas nas linhas de semeadura (ENDRES, 1996). De acordo com (KUSS et al., 2006), elevar a densidade de plantas tem sido uma forma alternativa de potencializar a produtividade de grãos de soja.

Esta é uma tendência atual na cultura, em que as densidades maiores, em torno de 10 a 18 plantas $\mathrm{m}^{-1}$, vêm sendo utilizadas com sucesso, pois além de não reduzirem significativamente a produtividade, proporcionam redução nos custos de produção pela redução nos gastos com sementes. Segundo Peixoto (1998), as plantas de soja compensam a redução ou aumento da densidade, por aumentarem a produção de vagens, o que contribui para maior tolerância à essa variação.

A elevação da produtividade das culturas devido ao melhor arranjo de plantas está associada ao aumento da radiação solar interceptada (ANDRADE et al., 2002). Sendo assim, para que sejam obtidas diferentes densidades de semeadura e, por conseguinte, populações de plantas, são necessárias variações na regulagem da semeadora-adubadora (CANOVA et al., 2007)

De acordo com Duncan (1986), existem três fases de resposta do rendimento de grãos de soja em função da densidade de plantas: fase I - a densidade de plantas é muito baixa, não se verifica competição entre plantas e o rendimento de grãos por planta é máximo; fase II - a planta começa a competir pelos recursos ambientais com a outra e fase III - caracterizada pela relação positiva entre o aumento na densidade de plantas e o aumento do rendimento de grãos por área, sendo o limite desta fase até interceptação da radiação fotossinteticamente ativa de $95 \%$ para se alcançar o máximo rendimento de grão por área.

A falta de resposta diferenciada do rendimento de grãos à variação da densidade de semeadura da soja está intimamente relacionada à plasticidade fenotípica que esta cultura apresenta (RAMBO et al., 2003). Segundo Tourino et al. (2002), o percentual de sobrevivência das plantas aumenta à medida que ocorre redução da densidade de semeadura, devido à competição intraespecífica das plantas, já que pelo aumento da densidade de semeadura, as alturas foram menores, provavelmente por serem uma característica genética.

Ludwig et al. (2007) ao estudar três densidades de semeadura de soja, 250000, 400000 e 550000 plantas por hectare, verificaram aumento na produção com o aumento da densidade, por outro lado, o número de vagens por planta diminuiu com o aumento das densidades. Os autores também verificaram que o número de grãos por vagem e a massa de grãos não variaram de acordo com as densidades.

O comportamento de cultivares de soja sob diferentes condições de cultivo se torna fundamental na busca do entendimento do manejo da cultura. Dessa forma a densidade de semeadura são práticas que devem ser aprimoradas para maior eficiência do sistema, sendo assim, a identificação de um número de plantas que resulte em uma competição intraespecífica que permita um melhor aproveitamento dos recursos disponíveis para o crescimento e rendimento de grãos é imprescindível.

Com base neste contexto, o presente trabalho teve por objetivo avaliar o comportamento agronômico de dois cultivares modernos de soja no município de Riolândia, localizado na região Noroeste do Estado de São Paulo, no ano agrícola 2017/18. 


\section{MATERIAL E MÉTODO}

O experimento foi implantado em condições de campo, no dia 10/11/2017 no Sítio Córrego da Anta de propriedade do Sr. Luis Carlos Tamura, situado no município de Riolândia, SP. O clima do local é considerado do tipo Aw (KÖPPEN, 1948), ou seja, clima tropical com estação seca no inverno e transição para clima subtropical, com chuvas no verão e relativamente seco no inverno.

Antes da instalação dos experimentos foram coletadas amostras de solo das áreas experimentais para posterior análise química e granulométrica. O solo da área experimental de Riolândia é classificado como Latossolo Vermelho Escuro Eutrófico, A moderado de textura muito argilosa, sendo instalado em semeadura direta na palhada de sorgo. De acordo com o laudo de análise química e física do solo, obtiveram-se os seguintes resultados: $\mathrm{pH}\left(\mathrm{CaCl}_{2}\right)=5,35 ;$ M.O. $=31,24 \mathrm{~g} \mathrm{dm}^{-3} ; \mathrm{CO}=18 \mathrm{~g} \mathrm{dm}^{-3} ; \mathrm{P}=42,74$ $\mathrm{mg} \mathrm{dm}{ }^{-3} ; \mathrm{K}=5,34 \mathrm{mmol}_{\mathrm{c}} \mathrm{dm}^{-3} ; \mathrm{Ca}=56,34 \mathrm{mmol}_{\mathrm{c}} \mathrm{dm}^{-3} ; \mathrm{Mg}=21,41 \mathrm{mmol}_{\mathrm{c}} \mathrm{dm}^{-3} ; \mathrm{H}+\mathrm{Al}=32,85 \mathrm{mmol}_{\mathrm{c}}$ $\mathrm{dm}^{-3} ; \mathrm{SB}=83,10 \mathrm{mmol}_{\mathrm{c}} \mathrm{dm}^{-3} ; \mathrm{CTC}=115,94 \mathrm{mmol}_{\mathrm{c}} \mathrm{dm}^{-3} \mathrm{e} \mathrm{V}=71,67 \%, \mathrm{~S}=16,85 \mathrm{mg} \mathrm{dm}^{-3}$; Areia Total $=$ $264 \mathrm{~g} \mathrm{~kg} \mathrm{de} \mathrm{solo}$; Argila $=525 \mathrm{~g} \mathrm{~kg}$ de solo e Silte $=209 \mathrm{~g} \mathrm{~kg} \mathrm{de} \mathrm{solo.} \mathrm{Em} \mathrm{porcentagem:} \mathrm{Areia} \mathrm{Total}=$ $26,40 \%$ (Areia grossa $=4,30 \%+$ Areia fina $=22,10 \%$ ); Argila $=52,50 \%$; Silte $=20,90 \%$.

O delineamento experimental utilizado foi em blocos ao acaso com parcelas sub-dividas ou "Split plot" e 4 repetições. O tratamento principal consistiu na utilização de duas cultivares comerciais: BRS 1074 IPRO - pertencente ao grupo de maturidade relativa 7.4 (semiprecoce), possuindo crescimento indeterminado e a cultivar BRS 1001 IPRO - pertencente ao grupo de maturidade relativa 6.2 (precoce), possuindo crescimento indeterminado, já as sub-parcelas consistiram em três densidades de semeadura: 8, 12 e 18 sementes por metro na linha de semeadura, totalizando população de plantas de 177777, 266666 e 400000, respectivamente. É importante ressaltar que foi realizado o ajuste da densidade para as subparcelas de acordo com a porcentagem de germinação fornecida pelo fabricante.

Para a implantação do experimento foi utilizada semeadora-adubadora modelo Hitech de 9 linhas, espaçada a $45 \mathrm{~cm}$, equipada com dosador de precisão na distribuição de fertilizantes sólidos, sistema pantográfico nas linhas de sementes e monitor de deposição de sementes PM 400 da empresa Valtra ${ }^{\circledR}$, garantido assim, a precisão na densidade de semeadura pré-estabelecida. A semeadora-adubadora foi tracionada por trator Jonh Deere ${ }^{\circledR}$ de 145 cv's operando na velocidade de $4,5 \mathrm{~km} \mathrm{~h}^{-1}$ e rotação na TDP de 540 rpm. Adotou-se a técnica da co-inoculação nas sementes (BARBÁRO-TORNELI et al., 2017), consistindo no uso de duas bactérias: Bradyrhizobium (cepa Semia 5080 e 5079) e Azospirillum brasilense (cepa AbV5), sendo realizada no sulco de semeadura, por meio do pulverizador Hunter 300 da empresa Orion $^{\circledR}$ acoplado ao chassi da semeadora-adubadora, na dosagem de $0,45 \mathrm{~L} \mathrm{ha}^{-1}$.

Todas as sementes foram previamente tratadas alguns dias da semeadura com inseticida/fungicida, Standak Top na dose de $0,002 \mathrm{~L} \mathrm{~kg}$ de sementes ${ }^{-1}$, sendo os inoculantes aplicados por último, no sulco de semeadura. Foi aplicado fertilizante contendo os micronutrientes cobalto e molibdênio, via pulverização foliar no estádio fenológico $\mathrm{V}_{5}$, em todos os tratamentos. Também foi efetuado o controle de doenças e pragas por meio de fungicidas e inseticidas quando necessário.

Todas as técnicas de cultivo da soja, como escolha de cultivar, época de semeadura, população de plantas, controle de plantas daninhas, insetos e doenças seguiram as recomendações técnicas para a cultura da soja da EMBRAPA (2013).

Por ocasião da maturação (R8), antes da colheita das parcelas úteis para estimação da produtividade dos grãos, avaliaram-se os seguintes caracteres de interesse agronômico:

- Altura de planta = dada pela distância do colo da planta até a extremidade da haste principal, em cm;

- Altura de inserção da primeira vagem = dada pela distância do colo da planta até a extremidade inferior da primeira vagem, em cm; 
- Índice de acamamento = de acordo com escala de notas proposta por Bernard, Chamberlain e Lawrence (1965), em que atribuiu-se nota de 1 - com todas as plantas eretas a 5 - com todas as plantas acamadas; - Estande final $=$ medidos em plantas por metro.

Foram avaliados também o peso de mil sementes $(\mathrm{g})$ e produtividade de grãos $\left(\mathrm{kg} \mathrm{ha}^{-1}\right)$, todas as plantas da área útil foram colhidas, separadas e identificadas para posterior trilhagem. Pesaram-se os grãos para cada parcela útil experimental $\left(4,5 \mathrm{~m}^{2}\right)$ e calculando-se a produtividade em $\mathrm{kg} \mathrm{ha}^{-1}$, sendo esta corrigida para teor de umidade de $13 \%$, conforme a Equação:

$$
\begin{gathered}
P F=P I \times \underline{100-U I} \\
100-U F
\end{gathered}
$$

Onde: PF: peso final da amostra (peso corrigido);

PI: peso inicial da amostra;

UI: umidade inicial da amostra, em percentagem;

UF: umidade final da amostra (13\%).

Os dados obtidos foram submetidos a análise de variância pelo teste $\mathrm{F}$, e as médias comparadas pelo teste de Tukey 5\%. Utilizou-se o programa estatístico AgroEstat (BARBOSA; MALDONADO, 2015).

\section{RESULTADO E DISCUSSÃO}

Na Tabela 1 estão descritos os resultados da análise de variância e médias gerais obtidas para os caracteres avaliados, em relação aos cultivares BRS 1074 IPRO e BRS 1001 IPRO em diferentes densidades de semeadura.

Os coeficientes de variação das variáveis analisadas se mantiveram dentro da faixa ideal para experimentos de campo, sendo aceitáveis para a cultura da soja indicando boa precisão dos resultados obtidos nas avaliações na média geral.

Para a população final de plantas, os resultados obtidos foram proporcionais ao aumento da densidade de semeadura, atingindo 297333 plantas para a densidade de 18 sementes por metro (Tabela 1), ou seja, com o aumento da densidade há aumento na população final, confirmando os resultados obtidos por Câmara et al. (1998) estudando o efeito da densidade e espaçamentos em soja, não havendo interação significativa com os cultivares, mostrando que os fatores cultivares e densidades agem independentemente entre si.

Quanto à altura de planta, na densidade de 18 sementes por metro observou-se crescimento significativamente maior em relação aos tratamentos com a densidade de 12 e 8 sementes por metro (Tabela 1), pelo provável estiolamento em busca de maior absorção e aproveitamento de luz, que ocorre em altas populações de plantas, concordando com Peluzio et al. (2000). As duas cultivares apresentaram alturas superiores à $60 \mathrm{~cm}$, considerada por Sediyama et al. (1999) a altura mínima da planta desejável para a realização da colheita mecanizada em solos de topografia plana a média declividade, destacando-se a cultivar BRS 1074 IPRO, com altura média de $95 \mathrm{~cm}$ (Tabela 1). Tal observação pode ser justificada pela cultivar ter o ciclo pouco mais longo que a cultivar BRS 1001 IPRO e possuir hábito de crescimento indeterminado.

Para altura de inserção da primeira vagem, observou-se diferença significativa entre as cultivares e densidades de semeadura. Com o aumento das densidades, verificou-se aumento na altura de inserção da 
primeira, com médias de 14,96; 17,40 e 19,31 para as densidades 8, 12 e 18 respectivamente (Tabela 1), obtendo resultados semelhantes aos observados por MARCHIORI et al. (1999) e MARTINS et al. (1999), que trabalharam com três cultivares e observaram aumento na altura de inserção da primeira vagem com o incremento do número de sementes metro ${ }^{-1}$ na linha de plantio. Esses resultados possivelmente estejam relacionados com a capacidade das cultivares para responderem às mudanças da população de plantas.

Tabela 1. Componentes de produção e rendimento de grãos avaliados cultivares de soja versus densidades de semeadura (a 45 cm entre linhas), Riolândia, SP, ano agrícola, 2017/18.

\begin{tabular}{|c|c|c|c|c|c|c|c|c|c|c|}
\hline Cultivares (C) & $\begin{array}{c}\text { População } \\
\text { final de } \\
\text { plantas }\end{array}$ & & $\begin{array}{c}\text { Altura d } \\
\text { planta } \\
\text { (cm) }\end{array}$ & & $\begin{array}{c}\text { Altura de } \\
\text { inserção } 1 \\
\text { vagem (cn }\end{array}$ & & Acamamento & $\begin{array}{c}\text { Produtividade } \\
\text { kg ha }^{-1}\end{array}$ & PMS & \\
\hline BRS 1074 IPRO & 10,46 & & 95,00 & & 16,14 & & 1,50 & 3.326 & 153,77 & \\
\hline BRS 1001 IPRO & 9,28 & & 83,91 & & 18,31 & & 1,50 & 3.045 & 176,70 & \\
\hline Teste F & $24,8=$ & $*$ & 424.54 & $* *$ & 579,43 & $* *$ & 1,01 ns & 8,93 ns & $3.973,34$ & $* *$ \\
\hline dms (Tukey 5\%) & 0,75 & & 1,71 & & 0,28 & & 0,43 & 299 & 1,15 & \\
\hline \multicolumn{11}{|l|}{ Densidade (D) } \\
\hline 8 & 6,40 & $\mathrm{c}$ & 81,06 & $\mathrm{c}$ & 14,96 & $\mathrm{c}$ & $1,00 \mathrm{~b}$ & 3.309 a & 171,86 & $\mathrm{a}$ \\
\hline 12 & 9,83 & $\mathrm{~b}$ & $90,34 \mathrm{~b}$ & b & 17,40 & $\mathrm{~b}$ & $1,37 \mathrm{~b}$ & $3.335 \mathrm{a}$ & 166,52 & $\mathrm{~b}$ \\
\hline 18 & 13,38 & $\mathrm{a}$ & 96,96 a & $\mathrm{a}$ & 19,31 & $\mathrm{a}$ & $2,12 \mathrm{a}$ & $2.912 \mathrm{~b}$ & 157,32 & $\mathrm{c}$ \\
\hline Teste F & $638.06=$ & $* *$ & 136.29 & $* *$ & 112,02 & $* *$ & $17,18 * *$ & $14,52 * *$ & 45,15 & $* *$ \\
\hline dms (Tukey 5\%) & 0.52 & & 2,58 & & 0,77 & & 0,52 & 234 & 4,13 & \\
\hline Interação C x D & $1.26^{\mathrm{r}}$ & ns & 17,13 & $* *$ & 9,37 & $* *$ & $0,82^{\text {ns }}$ & 3,17 ns & 13,03 & $* *$ \\
\hline média geral & 9,87 & & 89,45 & & 17,22 & & 1,50 & 3.185 & 165,23 & \\
\hline $\mathrm{CV}(\%)$ parcela & 5,90 & & 1,47 & & 1,27 & & 22,22 & 7,22 & 0,53 & \\
\hline CV (\%) sub parcela & 3,95 & & 2,16 & & 3,37 & & 26,05 & 5,51 & 1,87 & \\
\hline
\end{tabular}

Médias seguidas pela mesma letra na coluna, não diferem entre si pelo teste de Tukey a $5 \%$ de probabilidade. ${ }^{\text {ns }}=$ não significativo. $* *$ significativo a $5 \%$.

Segundo Sediayama et al. (1999), para que não haja perda na colheita, pelo sistema de corte e alimentação, a altura mínima da inserção da primeira vagem de ser de 10 a 12 centímetros, em solos de topografia plana e aproximadamente 15 centímetros, em solos de média declividade. Nas condições do experimento, a densidade de 8 sementes por metro pode vir a ter problemas de perdas na colheita em terrenos declivosos, por ter altura média de inserção em torno de $15 \mathrm{~cm}$ (Tabela 1).

Já para o peso de mil sementes, destaca-se a cultivar BRS 1001 IPRO com média de 176 gramas e a densidade de 8 sementes por metro na linha de semeadura com média de 171 gramas, corroborando com Val et al. (1971), na qual afirmou que há variação na massa de sementes com a mudança na densidade de plantas na linha. Weber et al. (1966) também obtiveram aumento desse componente agronômico relacionado ao aumento da população de plantas.

Verificou-se interação significativa entre cultivares e densidades de semeadura para os componentes agronômicos, altura de planta, altura de inserção da primeira vagem e para o peso de mil sementes (PMS).

Para as densidades de semeadura, verificou-se que a densidade de 18 sementes por metro na linha, atingiu melhores médias, nos componentes agronômicos altura de planta e altura de inserção da primeira 
vagem, 100,87 e 20,87 respectivamente, quando comparada com as densidades de 8 e 12 sementes por metro na linha, 94,25 e 15,56 respectivamente (Tabelas 2 e 3).

Tabela 2. Desdobramento da interação entre cultivares de soja e densidade de semeadura (a $45 \mathrm{~cm}$ entre linhas), para altura de plantas (cm), Riolândia, SP, ano agrícola 2017/18.

\section{Densidade de semeadura}

\begin{tabular}{|c|c|c|c|c|c|c|}
\hline Cultivar & 8 & 12 & 18 & & Teste F & Dms (Tukey 5\%) \\
\hline BRS 1074 IPRO & $89,87 \mathrm{Ca}$ & $94,25 \mathrm{Ba}$ & 100,87 & $\mathrm{Aa}$ & $32,74 * *$ & \multirow{3}{*}{3,65} \\
\hline BRS 1001 IPRO & $72,25 \mathrm{Cb}$ & $86,43 \mathrm{Bb}$ & 93,06 & $\mathrm{Ab}$ & $120,68 * *$ & \\
\hline Teste F & $201,91 * *$ & $39,67 * *$ & 39,67 & $* *$ & & \\
\hline Dms (Tukey 5\%) & & 2,66 & & & & \\
\hline
\end{tabular}

Médias seguidas pela mesma letra, maiúscula na linha e minúscula na coluna, não diferem entre si pelo teste de Tukey a $5 \%$ de probabilidade; $* *=$ significativo a $5 \%$.

Tabela 3. Desdobramento da interação entre cultivares de soja e densidade de semeadura (a $45 \mathrm{~cm}$ entre linhas), para altura de inserção da primeira vagem (cm), Riolândia, SP, ano agrícola 2017/18.

\begin{tabular}{|c|c|c|c|c|c|c|}
\hline \multicolumn{7}{|c|}{ Densidade de semeadura } \\
\hline Cultivar & 8 & & 12 & 18 & Teste F & Dms (Tukey 5\%) \\
\hline BRS 1074 IPRO & 15,10 & $\mathrm{Ba}$ & $15,56 \mathrm{Bb}$ & $17,75 \mathrm{Aa}$ & $23,37 * *$ & \multirow{3}{*}{1,09} \\
\hline BRS 1001 IPRO & 14,81 & $\mathrm{Ca}$ & $19,25 \mathrm{Ba}$ & $20,87 \mathrm{Ab}$ & $116,35 * *$ & \\
\hline Teste F & 0,81 & ns & $112,42 * *$ & $80,74 * *$ & & \\
\hline Dms (Tukey 5\%) & & & 0,75 & & & \\
\hline
\end{tabular}

Médias seguidas pela mesma letra, maiúscula na linha e minúscula na coluna, não diferem entre si pelo teste de Tukey a 5\% de probabilidade; $\mathrm{ns}=$ não significativo; $* *=$ significativo a $5 \%$.

De acordo com o desdobramento da interação, observou-se que a cultivar BRS 1001 IPRO atingiu médias superiores a 176 gramas, no componente agronômico peso de mil sementes, com diferença de 20 gramas quando comparada com a cultivar BRS 1074 IPRO (Tabela 4).

Tabela 4. Desdobramento da interação entre cultivares de soja e densidade de semeadura (a $45 \mathrm{~cm}$ entre linhas), para peso de mil sementes, Riolândia, SP, ano agrícola 2017/18.

\section{Densidade de semeadura}

\begin{tabular}{lrlrrrrr}
\hline Cultivar & $\mathbf{8}$ & $\mathbf{1 2}$ & $\mathbf{1 8}$ & Teste F & Dms (Tukey 5\%) \\
BRS 1074 IPRO & $155,87 \mathrm{Ab}$ & $148,59 \mathrm{Bb}$ & $156,86 \mathrm{Ab}$ & $8,52 * *$ & 5,84 \\
BRS 1001 IPRO & $187,85 \mathrm{Aa}$ & $166,05 \mathrm{Ca}$ & $176,17 \mathrm{Ba}$ & $49,65 * *$ & \\
Teste F & $307,33 * *$ & $91,65 * *$ & $112,04 * *$ & & & \\
Dms (Tukey 5\%) & & & 3,97 & & & &
\end{tabular}

Médias seguidas pela mesma letra na linha e na coluna não diferem entre si pelo teste de Tukey a 5\% de probabilidade; $* *=$ significativo a $5 \%$.

De acordo com análise de correlação de Pearson (Tabela 5), a produtividade $\mathrm{kg} \mathrm{ha}^{-1}$ possui correlação negativa em moderado grau com os componentes analisados agronomicamente, população final de plantas, altura de planta, altura de inserção da primeira vagem, acamamento e peso de mil semente 
ou seja, enquanto tal característica aumenta a outra por sua vez diminui.

Tabela 5. Análise de correlação de Pearson entre os componentes agronômicos e produtividade de soja, Riolândia, SP, ano agrícola 2017/18.

\begin{tabular}{lccccc}
\hline & $\begin{array}{c}\text { População } \\
\text { final de } \\
\text { plantas }\end{array}$ & $\begin{array}{c}\text { Altura de } \\
\text { planta } \\
\text { (cm) }\end{array}$ & $\begin{array}{c}\text { Altura de } \\
\text { inserção 1 } \\
\text { vagem }(\mathbf{c m})\end{array}$ & Acamamento & $\begin{array}{c}\text { Produtividade kg } \\
\text { ha }^{\mathbf{1}}\end{array}$ \\
\hline $\begin{array}{l}\text { Altura de planta } \\
(\mathrm{cm})\end{array}$ & $0,57^{* *}$ & - & - & - & - \\
$\begin{array}{l}\text { Altura de inserção } 1^{\mathrm{a}} \\
\text { vagem }(\mathrm{cm})\end{array}$ & $0,82^{* *}$ & $0,35 \mathrm{~ns}$ & - & - & - \\
$\begin{array}{l}\text { Acamamento } \\
\begin{array}{l}\text { Produtividade } \\
\text { kg ha1 }\end{array}\end{array}$ & $0,80^{* *}$ & $0,57^{* *}$ & $0,59^{* *}$ & - & - \\
PMS & $-0,50^{* *}$ & $-0,05 \mathrm{~ns}$ & $-0,56^{* *}$ & $-0,33 \mathrm{~ns}$ & - \\
\hline
\end{tabular}

ns = não significativo ${ }^{* *}=$ significativo a $5 \%$.

Verificou-se correlação positiva em forte grau entre as variáveis altura de planta e altura de inserção da $1^{\text {a }}$ vagem e entre a variáveis altura de planta e população final.

De acordo com Mauad et al. (2010), a produtividade da cultura está fortemente relacionada com a interação entre planta, ambiente de produção e manejo. A produtividade variou inversamente à variação da densidade das plantas na linha, ou seja, a redução da densidade provocou aumento na produção, variando entre 3308,75 e 2912,5 $\mathrm{kg} \mathrm{ha}^{-1}$, com diferença de 396,25 $\mathrm{kg} \mathrm{ha}^{-1}$ (Figura 1), resultados semelhantes foram encontrados por Ikeda (1992), Carpenter e Board (1997) e Peixoto (1998), o que, segundo Garcia (1992), ocorre por causa da capacidade da soja em ajustar os componentes de produção.

Figura 1. Produtividade das cultivares BRS 1074 IPRO e BRS 1001 IPRO em função das densidades de semeadura: 8, 12 e 18 sementes por metro na linha de semeadura (espaçadas à $45 \mathrm{~cm}$ ), Riolândia, $\mathrm{SP}$, ano agrícola 2017/18.

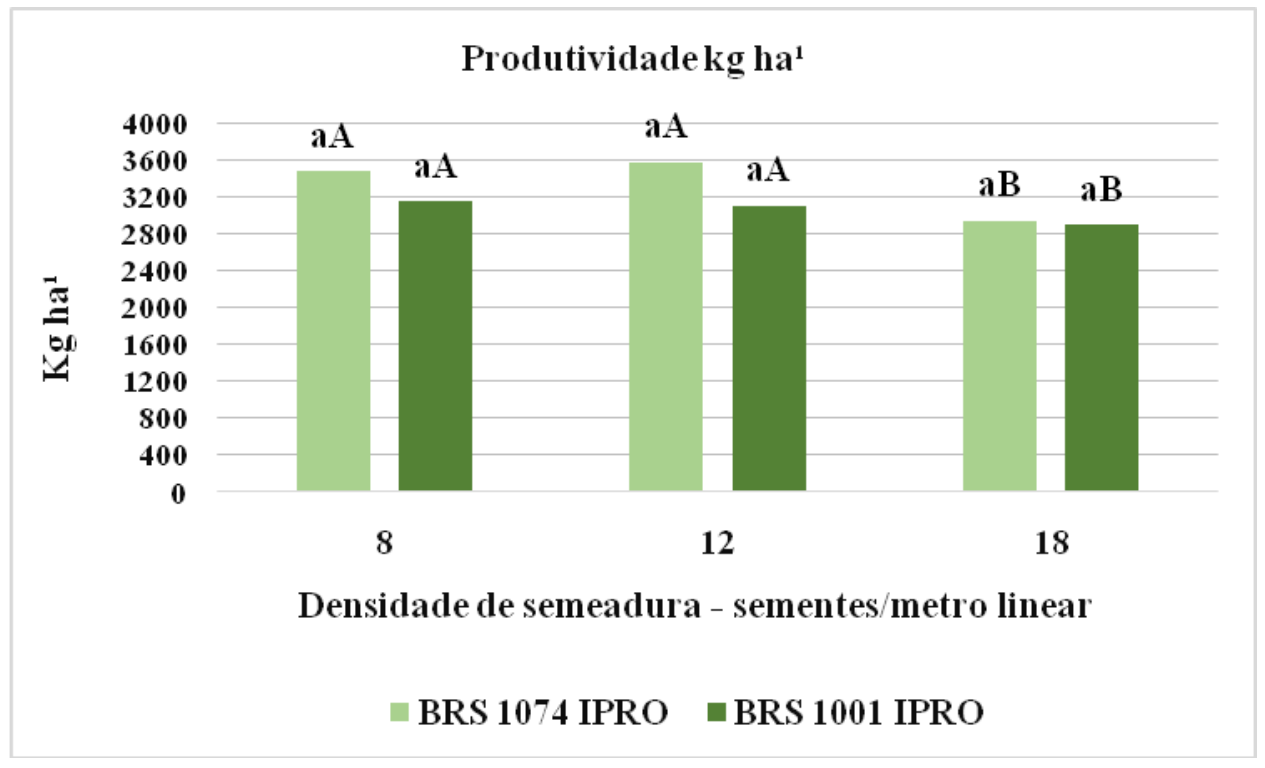

Nucleus, Edição Especial, 2018 


\section{CONCLUSÃO}

Com menor densidade populacional, as plantas são mais baixas, acamam menos, e apresentam maior porcentagem de sobrevivência.

Não houve diferença entre os dois cultivares de soja quanto à produtividade.

A produtividade diminuiu com o maior número de plantas na linha.

\section{AGRADECIMENTOS}

Ao produtor Luiz Carlos Tamura que cedeu a área para o desenvolvimento dos experimentos.

A todos os funcionários e estagiários da APTA e da CATI, pelo apoio na condução dos experimentos.

Às empresas J G Sementes, Coopercitrus - Cooperativa de Produtores Rurais e Orion Tecnologia e Sistemas Agrícolas Ltda, pelo apoio ao projeto que originou este trabalho.

\section{REFERÊNCIAS}

ANDRADE, F. H. Yield responses to narrow rows depend on increased radiation interception. Agronomy Journal, n. 94, n. 5, p. 975-980, 2002. Disponível em:http://dx.doi.org/10.2134/agronj2002.9750

BÁRBARO-TORNELI, I. M.et al. Viabilidade técnica e econômica da co-inoculação de soja no Estado de São Paulo. Nucleus, p. 45-58, 2017. (Edição Especial). Disponível em:

http://dx.doi.org/10.3738/1982.2278.2819

BARBOSA, J. C.; MALDONADO JUNIOR, W. AgroEstat - Sistema para Análises Estatísticas de Ensaios Agronômicos. Jaboticabal: UNESP, 2015.

BERNARD, R. L.; CHAMBERLAIN, D. W.; LAWRENCE, R. D. (Eds.). Result of the cooperative uniform soybeans tests. Washington: USDA, 1965. $134 \mathrm{p}$.

CÂMARA, G. M. S.et al. Desempenho vegetativo e produtivo de cultivares e linhagens de soja de ciclo precoce no município de Piracicaba-SP, Scientia Agrícola, v. 55, n. 3, p. 403-412, 1998. Disponível em: http://dx.doi.org/10.1590/S0103-90161998000300008

CANOVA, R.et al. Distribuição de sementes por uma semeadora adubadora em função de alterações mecanismo dosador e de diferentes velocidades de deslocamento. Engenharia na Agricultura, v. 15, n. 3, p. 299-306, 2007.

CARPENTER, A. C.; BOARD, J. E. Branch yield components controlling soybean yield stability across plant populations. Crop Science, v. 37, n. 3, p. 885-891, 1997. Disponível em:

http://dx.doi.org/10.2135/cropsci1997.0011183X003700030031x

CONAB - Companhia Nacional de Abastecimento. Indicadores Agropecuários: Estimativas 2018.

Disponível em: http://www.conab.gov.br

DUNCAN, W. G. Planting pattern sand soybean yields. Crop Science, v. 26, n. 1, p. 584-588, 1986.

EMBRAPA - EMPRESA BRASILEIRA DE PESQUISA AGROPECUÁRIA. Tecnologias de produção de soja - Região Central do Brasil 2014. Londrina: Embrapa Soja, 2013. 265 p.

Nucleus, Edição Especial, 2018 
ENDRES, V. C. Espaçamento, densidade e época de semeadura. In: EMBRAPA. Centro de Pesquisa Agropecuária do Oeste (Dourados, MS). Soja: recomendações técnicas para Mato Grosso do Sul e Mato Grosso. Dourados, 1996. p. 82-85. (Circular Técnica, 3).

GARCIA, A. Manejo da cultura da soja para alta produtividade. In: SIMPÓSIO SOBRE CULTURA E PRODUTIVIDADE DA SOJA, 1, 1991, Piracicaba. Anais... Piracicaba: Fealq, 1992. p. 213-235.

IKEDA, T. Soybean planting patterns in relation to yield and yield components. Agronomy Journal, v. 84, n. 6, p. 923-926, 1992. Disponível em:http://dx.doi.org/10.2134/agronj1992.00021962008400060002x

KÖPPEN, W. Climatologia. México. Fonndo de cultura econômica, 1948. 478 p.

KUSS, R. C. P. Populações de plantas e estratégias de manejo de irrigação na cultura da soja. 2006. 80 f. Dissertação (Mestrado) - Universidade Federal de Santa Maria, Santa Maria, 2006.

LUDWIG, M. P.et al. Efeito da densidade de semeadura e genótipos no rendimento de grãos e seus componentes na soja semeada após a época indicada. Revista da FZVA, v. 14, p. 13-22, 2007.

MARCHIORI, L. F. S. Desempenho vegetativo de cultivares de soja em épocas normal e safrinha. Scientia Agrícola, v. 56, n. 2, p. 383-390, 1999. Disponível em: http://dx.doi.org/10.1590/S0103-90161999000200018

MARTINS, M. C. Época de semeadura, densidades de plantas e desempenho vegetativo de cultivares de soja. Scientia Agrícola, v. 56, n. 4, p. 851-858, 1999. Disponível em: http://dx.doi.org/10.1590/S0103-90161999000400012

MAUAD, M.et al. Influência da densidade de semeadura sobre características agronômicas na cultura da soja. Agrarian, v. 3, n. 9, p. 175-181, 2011. Disponível em:https://doi.org/10.30612/agrarian.v3i9.75

PEIXOTO, C. P. Análise de crescimento e rendimento de três cultivares de soja em três épocas de semeadura e três densidades de plantio. 1998. $151 \mathrm{f}$. Tese (Doutorado) - Escola Superior de Agricultura Luiz de Queiroz, Piracicaba.

PELUZIO, J. M. Densidade e espaçamento de plantas de soja variedade Conquista em Gurupi, TO. Bioscience Journal, v. 16, p. 3-13, 2000.

RAMBO, L. COSTA, J. A.et al. Rendimento de grãos da soja em função do arranjo de plantas. Ciência Rural, v. 33, n. 3, p. 405-411, 2003. Disponível em: http://www.scielo.br/pdf/cr/v33n3/a03v33n3.pdf

SEDIYAMA, T.; TEIXEIRA, R. C.; REIS, M. S. Melhoramento da soja. In: BORÉM, A. (Eds.). Melhoramento de espécies cultivas. Viçosa: UFV, 1999. p. 487-533.

TOURINO, M. C. C.; REZENDE, P. M.; SALVADOR. N. Espaçamento, densidade e uniformidade de semeadura na produtividade e características agronômicas da soja. Pesquisa Agropecuária Brasileira, v. 37, p. 1071-1077, 2002. Disponível em:http://dx.doi.org/10.1590/S0100-204X2002000800004

VAL, W. M. C.et al. Efeito do espaçamento entre fileiras e da densidade na fileira sobre a produção de grãos e outras características agronômicas da soja. Experimentiae, v. 12, n. 12, p. 431-475, 1971.

WEBER, C. R.; SHIBLES, R. M.; BYTH, D. E. Effect of plant population and row spacing on soybean development and production. Agronomy Journal, v. 58, n. 1, p. 99-102, 1996. Disponível em: http://dx.doi.org/10.2134/agronj1966.00021962005800010034x 
